\title{
Application of expert systems in the construction sector
}

\author{
Arkadiusz Węglarz ${ }^{1 *}$ and Pawet Grzegorz Gilewski ${ }^{2}$ \\ ${ }^{1}$ Warsaw University of Technology, Faculty of Civil Engineering, al. Armii Ludowej 16, 00-637 \\ Warsaw \\ ${ }^{2}$ Warsaw University of Technology, Faculty of Building Services, Hydro and Environmental \\ Engineering, ul. Nowowiejska 20, 00-653 Warsaw
}

\begin{abstract}
Nowadays in the construction sector, there are many challenges regarding technical and economic problems as well as those associated with the impact on human health and environment. Solving these problems is not straightforward and requires the involvement of experts from different fields. Expert systems are interesting and complex solutions for the above-mentioned aspects. The article presents characteristics of Polish and world experts system in which the authors participated.
\end{abstract}

\section{Expert systems}

An expert system is a single or multiple sets of software which intends to support the use of knowledge and facilitate decision-making process [1,2]. Expert systems can assist or even replace human experts in a certain field. They can provide the user with advice, recommendations or diagnosis in the problems related to the study field.

The following characteristics distinguish expert systems from conventional systems:

- explicit representation of knowledge,

- application to solving specific problems according to the reasoning procedures (inference)

- ability to explaining the solutions found by the system,

- knowledge processing mainly concerns symbol processing rather than numerical computations.

Unlike classical software knowledge in the knowledge, database describes the problem domain without providing an exact algorithm for solving a given problem. Knowledge is written according to a specific knowledge representation language, most commonly consisting of:

- description of the facts,

- description of the rules used in the inference process,

- meta description of rules that show a strategy for solving the problem,

A typical expert system is shown in Fig. 1.

*Corresponding author: a.weglarz@il.pw.edu.p1 


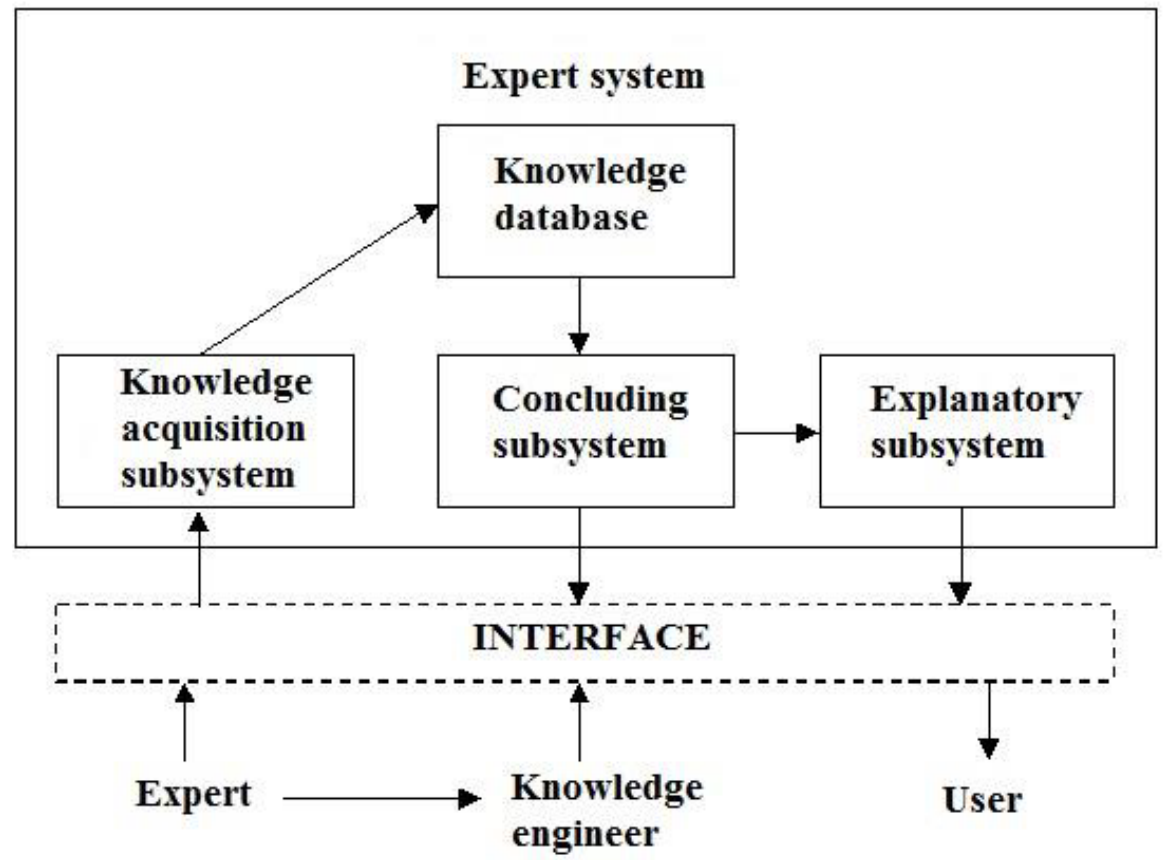

Fig. 1. Diagram of expert system (own elaboration based on: http://www.rosczak.com/mlp/ai.html)

\section{Existing expert systems in the construction sector}

One of the first expert systems in the construction sector was HI-RISE program which was elaborated to help with the design of tall buildings [3]. Another interesting program is called ScaRC and is used to create construction schedules during the construction of repeatable storey floors [3]. The expert system called RUMBAu uses the 3D technique to design wall formations in the PERI TRIO system. Also, the ELPSON program is used for the support in decors design in the PERI system. It is characterized by such a level of service simplicity that it can be used by people with very little professional experience. An interesting diagnostic system called REPCON is used during the assessment of buildings structure damage. It also provides hints and proposes methods for repairing them.

The system SPERIL [4] is being developed at Purdue University. Its aim is to analyze the building damage which results from hazardous events such as an earthquake or roof overload due to precipitation. It proposes a mathematical model of analysis, using rules of the IF-THAT'S-DIFFERENT type. The inaccuracy of reasoning is modeled by fuzzy logic (between truth and falsity there are many indirect values), and the full program is implemented in C-language.

For the evaluation of a construction investment, the HICOST program [3] was implemented as a rule-based program. It consists of a series of subsystems to find the cost of the building's components.

The application called COMVOC proposes support for project planning while operating on estimates of the final value of the construction project as a function of decisions affecting the project. It allows exporting the resulting database to the well-recognized MS environment. 
The ACPROM system [5] provides support for the investment implementation phase, estimating the progress of building works based on project and photographic documentation, allowing to export the resulting databases to MS Project. It allows to integrate:

- executive drawings,

- digital pictures of the construction site,

- digital progress photography,

for project monitoring and decision support by the building process managers. As a result of the system automatically interprets the drawings in [*.dwg] format and extracts construction element data so that, comparing the above with digital images, generate information about the percentage progress of the planned work.

The "Value Management for Construction Projects" program supports the process of identifying financial parameters for construction projects. The process of acquiring knowledge into the system consists of an aggregation of knowledge available in the literature on value management in the construction industry by means of a checklist and knowledge available from experts using the submitted forms. It was implemented in $\mathrm{C}++$ and later verified by experts in the field of value management.

The COMIX program [6] has an advisory role in the design of concrete mix based on New Zealand standards. It is based on rules and framework and helps to choose the type of mix and the type of construction, calculates the correct ratio for the appropriate load and sand mass, aggregate and all concrete components.

The BIDEX program offers support of the process of preparation of offers for a given building objects. It is used by construction engineers when making bid decisions. Built using the expert system shell "Exsys", the program makes a decision in two stages. The first decision concerns the cost of works, materials, and equipment. The second decision concerns the size of the overheads. This last decision includes the type of owner, type of work, the size of work, place of work, market power, the degree of danger and confidence level of subcontractors.

The platform "Advisory System for Managers" [6] platform is an operational prototype of decision support for planning and management of building projects that can be used by building managers in their day-to-day duties and during the pre-design phase. So far the program has been used to analyze small projects. The main purpose of the application is to systematize the decision-making process. It includes models of cost, raw materials, administration. The system has mainly an advisory function, among others like:

- information management,

- financial management,

- current and future technical problems on the construction site.

The CONFAULT system is intended to support diagnostic processes related to defects in reinforced concrete construction by identifying subgroups of defects. The knowledge database of the program is divided into modules corresponding to the six basic types of defects. Metadata are used to control and restrict the research. The original approach to confidence allows uncertainty modeling.

\section{Expert system for the building energy source selection}

At the University of Zielona Góra the "Expert system for the selection of energy source for the building" [7] has been created in the framework of the research task No. 6 "Analysis of technical and operational requirements for buildings with power from centralized heat sources", implemented as a part of the strategic project "Integrated system for reducing the energy consumption of buildings". The concept of the system was based on the integration 
of many computing tools to create a unified computer system supported by knowledge databases.

The main purpose of the expert system is to analyze the energy of a given building or group of buildings and to make recommendations on energy sources based on $\mathrm{CO}_{2}$ emissions and investment costs based on the indicators contained in knowledge databases.

The expert system consists of nine major elements:

- module for entering and editing data of research buildings,

- the input generation module for the simulation application (EnergyPlus) calculating the energy characteristics of the researched buildings,

- simulation application based on ready-made calculation engine (EnergyPlus),

- input file generation module for calculation and selection of energy source,

- an independent calculation module prepared in the MATLAB environment and designed to calculate and select a source of energy for a research building (including a centralized source) based on $\mathrm{CO}_{2}$ emission,

- investment analysis module for the construction of district heating and local energy sources for the needs of a group of buildings,

- investment analysis module related to the necessary repairs of the district heating network when the recommendation concerns a centralized energy source for a group of buildings,

- investment analysis module for an embedded energy source,

- the module of recommendations for energy sources based on $\mathrm{CO}_{2}$ emission and investment costs of the heat source.

- executive drawings,

The expert system for both pathways conducts all analyses considering the following possibilities of the recommendation of energy sources.

Analysis of a single building:

- energy source built into the facility (gas or oil boiler room),

- built-in microgeneration unit,

- inserting the building into an existing heating system with a centralized heat source.

Analysis of a group of buildings:

- energy source built into each building separately (gas or oil boiler room),

- heating micro-grid with group energy source in the form of gas or oil boiler room,

- heating micro-grid with a group of energy sources in the form of a micro-cogeneration unit,

- inserting a group of buildings into an existing district heating system with a centralized heat source.

As a result, the expert system provides a list of energy recommendations for a single building or group of buildings that can be ranked on both criteria, i.e. $\mathrm{CO}_{2}$ emissions and estimated investment costs, or only one criterion.

The software is ideal for the decision support, investment planning related to changes in the way that heat is supplied to buildings or small settlements. Due to its expert nature, it can also be regarded as an advisory tool for planning changes in the energy policy of a settlement unit.

\section{Description of the expert system supporting the energy management process in a smart single-family house}

In a properly newly designed and constructed an energy-saving building or in a deeply thermo-modernized existing building the theoretically calculated energy-saving effects are often not achieved. There are many reasons for that. One of them is poor management of energy in the process of building operation. The solution to this problem can be the use of 
smart building systems such as the KNX system. Such issues have already been described in the literature $[8,9]$. However, the problem is complicated when dealing with energy management in buildings with hybrid systems of heat and cold production such as gas boiler and wood burning fireplace. At this point, it is advisable to use expert systems to control the KNX installation.

In order to get the database input for the expert system controlling the KNX installation in a single-family house, the calculation of the demand for heat and cold (power and heat/cold consumption) was made using the hourly method using the Design Bilder program. The subject of the study was a multi-generation single-family house located in Warsaw. The analyses were conducted for the standard year (365 days) and the year with extreme weather conditions (frosty winter and hot summer).

The simulation results are shown in Fig. 2.

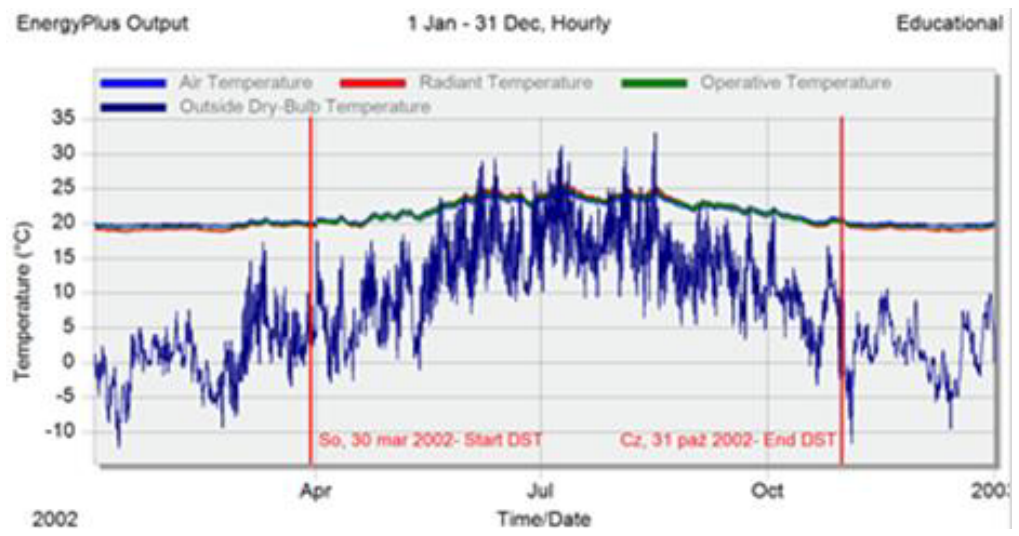

Fig. 2. Design Bilder simulation results.

The purpose of the expert system is to determine when to run the selected device so that the final energy consumption of the indoor climate control system (energy management) is minimal and the costs as small as possible.

The expert system must decide whether to start heating or cooling. The KNX system will do it.

In the case of the heating mode the following options are available:

- turn on the ground source heat pump,

- activate the electric heater for supply air $(1 \mathrm{~kW})$,

- start the electric heater for supply air $(3 \mathrm{~kW})$ and turbine with the productivity of 540 $\mathrm{m}^{3} / \mathrm{h}$,

- start the fireplace $(15 \mathrm{~kW})$ and turbine with the productivity of $700 \mathrm{~m}^{3} / \mathrm{h}$.

For cooling mode, the following options are available:

- turn on the ground source heat pump,

- active the cooler for supply air $(1 \mathrm{~kW})$,

- active the cooler for supply air $(3 \mathrm{~kW})$ and turbine with the productivity of $540 \mathrm{~m}^{3} / \mathrm{h}$.

Each room has the option of setting the required internal temperature with a KNX thermostat that controls the throttle located before the diffusers in the DGP Hot Air Distribution System. If all the throttles are closed then the turbine is shut down. If all are fully open then the turbines are running at a maximum efficiency. In intermediate states, the productivity of turbines and the opening of throttles is proportionally controlled. 
Considering the results of the simulation of Design Bilder, the following rules of the expert system are proposed:

Heating season $=($ Yes $/$ No $)$

$t_{\mathrm{z}}$ - temperature on the external sensor,

$\mathrm{t}_{\mathrm{w}}{ }^{\max }$ - maximum value from temperature measurements on sensors inside the building $\left[{ }^{\circ} \mathrm{C}\right]$.

\section{Rule 1:}

If $\mathrm{t}_{\mathrm{z}} \leq-5^{\circ} \mathrm{C}$ or $\mathrm{t}_{\mathrm{z}} \geq 25^{\circ} \mathrm{C}$ then turn on the ground source heat pump, otherwise follow the Rule 2.

\section{Rule 2:}

If $\mathrm{t}_{\mathrm{z}}>-5^{\circ} \mathrm{C}$ and $\mathrm{t}_{\mathrm{z}}<25^{\circ} \mathrm{C}$ then turn off the ground source heat pump from the ventilation system.

\section{Rule 3:}

If the temperature sensor over the fireplace indicates a temperature of $>30^{\circ} \mathrm{C}$ and at least one throttle is open, then turn on the turbine with a capacity of $700 \mathrm{~m}^{3} / \mathrm{h}$.

\section{Rule 4:}

If $\mathrm{t}_{\mathrm{w}}{ }^{\max }>26^{\circ} \mathrm{C}$ then start up the supply air cooler with $1 \mathrm{KW}$ and turn off the heater.

\section{Rule 5:}

If $\mathrm{t}_{\mathrm{w}}{ }^{\max }>26^{\circ} \mathrm{C}$ and a $1 \mathrm{KW}$ ventilated air cooler was switched on and the heating was switched off then start up a $3 \mathrm{KW}$ cooling radiator and the turbine of a capacity of 540 $\mathrm{m}^{3} / \mathrm{h}$.

\section{Rule 6:}

If Heating season $=$ Yes and the temperature sensor over the fireplace indicates a temperature of $<20^{\circ} \mathrm{C}$ and at least one throttle is open then start up $3 \mathrm{~kW}$ heater and the turbine of a capacity of $540 \mathrm{~m}^{3} / \mathrm{h}$.

The system was launched in September 2016 and the first results show the correctness of the assumed thesis and the convergence of the results of the digital simulation with measurements of the outside and inside temperatures.

\section{Summary and conclusions}

In the world construction industry, for many years, the expert systems have been used to support decision-making at every stage of the investment process from design to building use. Unfortunately, in Poland, the use of these artificial intelligence tools is still very rare. This is due to the building tradition and the awareness of the participants in the building process: investors, designers, contractors and property managers. In recent years, the concept of native expert systems has emerged as an example of the systems described above. It seems necessary to develop further research in this field towards hybrid artificial intelligence systems with the key role of expert systems.

\section{References}

1. J. Mulawka, Expert systems [in Polish] (Wydawnictwo Naukowo-Techniczne, 1997)

2. R. Tadeusiewicz, XVI Conference of Automation Rytro (CD), (2012)

3. D.R. Rehak, S.J. Fenves, Expert systems in civil engineering, construction and construction robotics (Research Showcase CMU, 1984)

4. S.J. Fenves, M.L. Mahler, D. Siriam, IABSE PER. 4, 63 (1985) 
5. Z.A. Memon, First International Conference on Construction in Developing Countries (ICCIDC-I, 2008)

6. M. Akram, I.A. Rahman, I. Memon, Int. Jour. of Civ. Engin. and Bui. Env., 1, 24 (2014)

7. P. Ziembicki, A. Węglarz, Ciepłownictwo, Ogrzewnictwo, Wentylacja, 5,?? (2013)

8. R. Radajewski, A. Kamińska, Elektro.info 11,?? (2008)

9. M. Horyński, Energy-efficient automated energy management systems in residential buildings (Wyd. Pol. Lub., 2015) 